\title{
Desenvolvimento das plantas e produtividade de tubérculos de batata em clima subtropical ${ }^{1}$
}

\author{
Plant development and tuber yield in the potato in a subtropical climate
}

\author{
Alencar Junior Zanon ${ }^{2}$, Nereu Augusto Streck ${ }^{3 *}$, Bruno Kräulich ${ }^{4}$, Michel Rocha da Silva ${ }^{2}$ e Dílson Antônio \\ Bisognin $^{3}$
}

\begin{abstract}
RESUMO - Os objetivos deste trabalho foram caracterizar desenvolvimento das plantas e determinar a produtividade de tubérculos de clones avançados de batata em duas épocas de cultivo (outono e primavera) em ambiente subtropical do Rio Grande do Sul. Foram avaliados dez clones avançados do Programa de Genética e Melhoramento de Batata da Universidade Federal de Santa Maria e duas cultivares (Asterix e Macaca). Foram determinados: número de folhas acumuladas na haste principal, número final de folhas, filocrono, evolução do índice de área foliar verde, índice de área foliar máximo, duração em dias das fases plantio-emergência, emergência-início de tuberização, início de tuberização-início de senescência e emergência-início da senescência e a massa fresca e seca de tubérculos. Ocorreu uma variação do filocrono, número final de folhas e da evolução do índice de área foliar em função do genótipo, em cada época de cultivo. Comparando os cultivos de primavera e outono, e descontando-se a fase plantio-emergência, a duração das fases do ciclo de desenvolvimento da batata foram, em geral, menores no cultivo de outono. Verificou-se que a duração das fases emergência-início de tuberização e início de tuberização-início de senescência determinam a produtividade de tubérculos. Exceto o clone SJSM 03478-37, os clones avançados apresentam elevada produção de tubérculos e boa adaptação às duas épocas de cultivo em ambiente subtropical do Rio Grande do Sul.
\end{abstract}

Palavras-chave: Batata. Fenologia Vegetal. Análise foliar.

\begin{abstract}
The objectives of this study were to characterize plant growth and determine the productivity of tubers in advanced potato clones during two growing seasons (autumn and spring) in a subtropical environment in the State of Rio Grande do Sul. Ten advanced clones from the Potato Genetics and Breeding Program of the Federal University of Santa Maria, and two cultivars (Asterix and Macaca) were evaluated. The following were all determined: number of accumulated leaves on the main stem; final number of leaves; phyllochron; evolution of the green-leaf area index; maximum leaf-area index; phase duration in days for planting to emergence, for emergencence to tuber initiation, tuber initiation to start of senescence, and emergence to start of senescence; tuber fresh and dry matter. There was a variation in phyllochron, final leaf number and evolution of the leaf-area index as a function of genotype, for each growing season. Comparing the spring and fall crops, and excluding the planting to emergence phase, phase duration in the development cycle of the potato was generally lower for the autumn crop. It was found that phase durations for emergence to tuber initiation, and tuber initiation to the start of senescence, determine tuber productivity. Except for the SJSM 03478-37 clone, advanced clones present a high tuber yield and good adaptation to the two cropping seasons in the subtropical environment of Rio Grande do Sul
\end{abstract}

Key words: Potato. Crop Phenology. Leaf Analysis.

\footnotetext{
*Autor para correspondência

${ }^{1}$ Recebido para publicação em 07/05/2012; aprovado em 30/06/2013

Extraído da Dissertação de Mestrado do primeiro autor, bolsista da Capes

${ }^{2}$ Programa de Pós-Graduação em Agronomia, Universidade Federal de Santa Maria, Santa Maria-RS, Brasil, alencarzanon@hotmail.com, michelrs@live.com ${ }^{3}$ Departamento de Fitotecnia, Centro de Ciências Rurais, Universidade Federal de Santa Maria, Santa Maria,-RS, Brasil, nstreck2@yahoo.com.br, dbisognin@gmail.com

${ }^{4}$ Engenheiro Agrônomo, In memoriam
} 


\section{INTRODUÇÃO}

A batata é a terceira cultura alimentícia na ordem de importância no mundo, depois do trigo e arroz (VISSER et al., 2009). No Brasil, é a hortaliça de maior importância econômica, apresentando, na safra de 2011, produção de 3.876.103 t, numa área de 146.909 ha, e produtividade média de 26,4 $\mathrm{t} \mathrm{ha}^{-1}$ (INSTITUTO BRASILEIRO DE GEOGRAFIA E ESTATÍSTICA, 2011). No Rio Grande do Sul (RS) foram plantados em 2011 aproximadamente 22.000 ha, com produtividade média de $17,2 \mathrm{t} \mathrm{ha}^{-1}$ (INSTITUTO BRASILEIRO DE GEOGRAFIA E ESTATÍSTICA, 2011). Atualmente, a maioria das cultivares de batata plantadas no Brasil são oriundas de programas de melhoramento da Europa e América do Norte (SOUZA, 2010), sendo pouco adaptadas a temperaturas elevadas (MENEZES et al., 2001) e fotoperíodo curto (RODRIGUES et al., 2009), o que reduz o potencial produtivo e a qualidade dos tubérculos em condições tropicais e subtropicais de cultivo.

A temperatura, o fotoperíodo e a radiação solar são os fatores abióticos que governam o crescimento, o desenvolvimento e a produtividade da cultura da batata (BISOGNIN et al., 2008). Temperaturas elevadas favorecem o crescimento da parte aérea e reduzem a produção e a qualidade de processamento dos tubérculos (HELDWEIN; STRECK; BISOGNIN, 2009). Segundo Streck et al. (2007), a planta de batata é de dia curto para início de tuberização e neutro ou de dia longo para florescimento.

$\mathrm{Na}$ maioria das regiões produtoras de batata do Rio Grande do Sul são realizados dois cultivos por ano (outono e primavera). Nestas duas épocas, há aproximadamente 100 dias de condições meteorológicas favoráveis para o crescimento e desenvolvimento da planta (SOUZA, 2010). Logo, as cultivares adaptadas a essas regiões devem apresentar tubérculos com curta dormência, elevado índice de área foliar (IAF) no início da tuberização e ciclo de desenvolvimento curto. Comparando-se as duas épocas de cultivo, na primavera as condições meteorológicas são mais favoráveis ao crescimento e desenvolvimento das plantas, proporcionando maior rendimento e qualidade de tubérculo, enquanto no cultivo de outono, o crescimento e o desenvolvimento das plantas de batata são limitados pelas altas temperaturas no início do ciclo de desenvolvimento e pela baixa disponibilidade de radiação solar na segunda metade do ciclo de desenvolvimento (BISOGNIN et al., 2008; BURIOL et al., 2006). Assim, o desafio nos programas de melhoramento é desenvolver clones de batata adaptados e produtivos nas duas estações de cultivo das regiões subtropicais do Rio Grande do Sul.
Os objetivos deste trabalho foram caracterizar o desenvolvimento das plantas e determinar a produtividade de tubérculos de clones avançados de batata em duas épocas de cultivo (outono e primavera) em ambiente subtropical do Rio Grande do Sul.

\section{MATERIAL E MÉTODOS}

Foram conduzidos dois experimentos de campo, um na primavera de 2010 e o outro no outono de 2011 em Santa Maria, RS (latitude de $29^{\circ} 43^{\prime} \mathrm{S}$; longitude de $53^{\circ} 43^{\prime}$ W e altitude de $95 \mathrm{~m}$ ). O clima da região, segundo a classificação climática de Köppen, é do tipo fundamental Cfa, subtropical úmido com verões quentes e sem estação seca definida (KUINCHTNER; BURIOL, 2001). O solo dos cultivos é uma transição entre a Unidade de Mapeamento São Pedro (Argissolo Vermelhodistrófico arênico)e a Unidade de Mapeamento Santa Maria (Argissolo Bruno Acinzentado úmbrico).

Foram avaliados doze genótipos de batata, sendo duas cultivares comerciais (Asterix e Macaca), por serem as mais plantadas no Rio Grande do Sul, e dez clones avançados do Programa de Genética e Melhoramento de Batata (PGMB) da Universidade Federal de Santa Maria: SMINIA00017-6, SMINIA793101-3, SMINIA02106-11, SJSM00211-3, SJSM03478-37, SJSM01212-2, SJSM012744, SJSM04503-9, SJSM02349-1 e SJSM02317-3. Os clones avançados foram selecionados pelo PGMB/UFSM devido à sua alta qualidade de chips. $\mathrm{O}$ delineamento experimental foi blocos ao acaso com sete repetições. A unidade experimental foi uma fileira com 3,3 m de comprimento, contendo dez covas. A densidade de plantio foi de 3,79 covas $\mathrm{m}^{-2}$ dispostas no espaçamento de $0,80 \mathrm{~m}$ entre fileiras e de $0,33 \mathrm{~m}$ entre plantas. Em cada lado da área útil do experimento foram plantadas duas linhas de bordadura.

As datas de plantio (PL) foram 24/08/2010 e 17/02/2011, que estão dentro do período recomendado de julho a setembro, para o cultivo de primavera, e de janeiro a março, para o cultivo de outono (HELDWEIN; STRECK; BISOGNIN, 2009). Os tubérculos-semente utilizados em ambos os cultivos tinham diâmetro entre 35 e $50 \mathrm{~mm}$ e foram submetidos ao processo de cura por 15 dias a $20^{\circ} \mathrm{C}$ logo após a colheita e depois foram tratados com ácido giberélico para acelerar a quebra da dormência das gemas e armazenados a $10^{\circ} \mathrm{C}$ em câmara climatizada até o plantio.

Considerou-se como data de emergência quando $50 \%$ das covas apresentavam pelo menos uma planta visível acima do solo. Após a emergência, quatro plantas em cada unidade experimental foram identificadas, e nelas foram medidas as variáveis de crescimento e desenvolvimento: número de folhas acumuladas na 
haste principal (NF), área foliar (AF), número final de folhas (NFF) e a data do início da senescência (IS).

O NF foi contado duas vezes por semana na haste principal até a emissão da última folha (NFF). A folha foi considerada como visível quando o folíolo apical media pelo menos $1 \mathrm{~cm}$ de comprimento (STRECK et al., 2009). Semanalmente foi medido o comprimento das folhas verdes (C), a partir da inserção do pecíolo na haste principal até o ápice do folíolo central, em uma cova da unidade experimental, em três repetições. A área de cada folha foi estimada a partir do $\mathrm{C}$ através de equações de regressão não linear entre $\mathrm{AF}$ e $\mathrm{C}$ para cada clone com o auxílio do programa Table Curve 2D Windows v. 2.03 e selecionada a equação com maior coeficiente de determinação $\left(R^{2}\right)$. $O$ índice de área foliar (IAF) verde foi calculado somando-se as áreas individuais de folhas e dividindo-se pela área de solo ocupada por uma cova $\left(0,26 \mathrm{~m}^{2}\right)$.

Adata do início da tuberização(IT) foi determinada coletando-se, a cada dois dias, quatro plantas de cada clone nas linhas da bordadura. Foi considerado o dia do IT quando $50 \%$ das plantas amostradas apresentaram pelo menos um tubérculo com $1 \mathrm{~cm}$ de diâmetro (STRECK et al., 2007). No dia da ocorrência do IT foi contado o número de folhas (NF no IT) e determinado o índice de área foliar (IAF no IT) das plantas amostradas. A data do início da senescência (IS) foi considerada quando $50 \%$ das plantas marcadas na parcela estavam no estágio de início de senescência conforme a escala de Heldwein, Streck e Bisognin (2009). No estágio IS realizou-se a coleta dos frutos nas quatro plantas identificadas para a determinação da massa da matéria seca.

As temperaturas mínima e máxima diária do ar durante o período experimental foram medidas na estação meteorológica convencional pertencente ao $8^{\circ}$ Distrito de Meteorologia do Instituto Nacional de Meteorologia $\left(8^{\circ}\right.$ DISME/INMET), localizada a aproximadamente $100 \mathrm{~m}$ da área experimental. A soma térmica diária $\left(\mathrm{STd},{ }^{\circ} \mathrm{C}\right.$ dia) foi calculada por (ARNOLD, 1960): STd = (Tmed - Tb). 1 dia, e se Tmed $<$ Tb então Tmed $=\mathrm{Tb}$, em que: Tmed é a temperatura média do ar, calculada pela média aritmética das temperaturas máxima e mínima do ar, e $\mathrm{Tb}$ é a temperatura base de desenvolvimento da batata $\left(\mathrm{Tb}=7^{\circ} \mathrm{C}\right)$ (PAULA et al., 2005). A STd foi acumulada a partir do plantio, resultando na soma térmica acumulada (STa), ou seja: $\mathrm{STa}=\sum$ STd. Para cada planta foi estimada a regressão linear entre o NF e a STa. O filocrono foi estimado pelo inverso do coeficiente angular da regressão linear entre NF e STa (XUE; WEISS; BZENZIGER, 2004).

A colheita dos tubérculos e da parte aérea das plantas foi realizada em 16/12/2010 no cultivo de primavera e apenas dos tubérculos em 16/06/2011 no cultivo de outono. Na colheita do cultivo de primavera a parte aérea ainda estava verde e no cultivo de outono, no dia da colheita a parte aérea estava morta devido a uma geada que ocorreu 10 dias antes da colheita e, portanto não foi avaliada. Os tubérculos foram classificados pelo menor diâmetro em pequenos (15-35 $\mathrm{mm})$, médios (35-55 mm) e grandes (> $55 \mathrm{~mm})$. A massa da matéria fresca (MF) de tubérculos por cova foi quantificada no momento da colheita e, posteriormente, dez tubérculos de cada clone foram colocados em estufa de ventilação forçada a $60{ }^{\circ} \mathrm{C}$ até massa constante, para determinação da massa da matéria seca (MS) de tubérculos.

Os dados de filocrono, NFF, MF e MS de tubérculos foram submetidos à análise da variância e as médias foram comparadas pelo teste Tukey $(\mathrm{p}<0,05)$. Os dados de MF e MS de tubérculos foram submetidos à análise de correlação de Pearson com a duração das fases PL-EM, EM-IT, IT-IS, EM-IS, IAF no IT, IAFmax, NF no IT, NFF e massa seca de frutos e massa seca da parte aérea, considerando-se significância de $\mathrm{p}<0,01$ e de $\mathrm{p}<0,05$. Todas as análises estatísticas foram realizadas com auxílio do pacote estatístico SAS.

\section{RESULTADOS E DISCUSSÃO}

As temperaturas mínimas (TMIN) e máximas (TMAX) do ar foram crescentes ao longo da estação de crescimento no cultivo de primavera (Figura 1a) e decrescentes, no cultivo de outono (Figura 1b).

O fim do inverno/2010 teve elevada precipitação, e por isso as quatro primeiras semanas após o plantio do cultivo de primavera foram predominantemente de dias nublados e chuvosos (Figura 1c). Já a primavera/2010, o verão 2010-2011 e o outono/2011 foram marcados por chuvas abaixo da média normal (Figura 1c, 1d), associado com a ocorrência do fenômeno La Niña. Ao longo da estação de crescimento da cultura, a disponibilidade de radiação solar aumentou durante o ciclo de desenvolvimento no cultivo de primavera e o inverso ocorreu no cultivo de outono (Figura 1e e 1f). As plantas de batata foram expostas, na primavera, a variação do fotoperíodo de 12,1 a 14,9 horas (Figura 1e) e no cultivo de outono ocorreu variação decrescente do fotoperíodo de 13,7 a 11,1 horas (Figura 1f).

Houve maior duração e desuniformidade da emergência no cultivo de outono que no de primavera (Figura 2), devido à dormência dos tubérculos usados no outono não ter sido completamente superada, uma vez que o período entre a colheita $(16 / 12 / 2010)$ e o plantio (17/02/2011) dos tubérculos usados como batata-semente no cultivo de outono foi pequena, apenas 61 dias, visto que o rompimento da dormência dos tubérculos pode demorar até 170 dias (MÜLLER et al., 2010). Destaca-se 
Figura 1 - Temperaturas mínimas (TMIN) e máximas (TMAX) diárias do ar (a, b), precipitação (mm dia-1 $)$ (c, d) e densidade de fluxo de radiação solar global incidente $\left(\mathrm{MJ} \mathrm{m}^{-2} \mathrm{dia}^{-1}\right)$ e fotoperíodo $(\mathrm{e}, \mathrm{f})$ durante o período experimental da batata no cultivo de primavera de 2010 (24/08/2010 a 16/12/2010) e no cultivo de outono de 2011 (17/02/2011 a 16/06/2011) em Santa Maria, RS, $2010-2011$
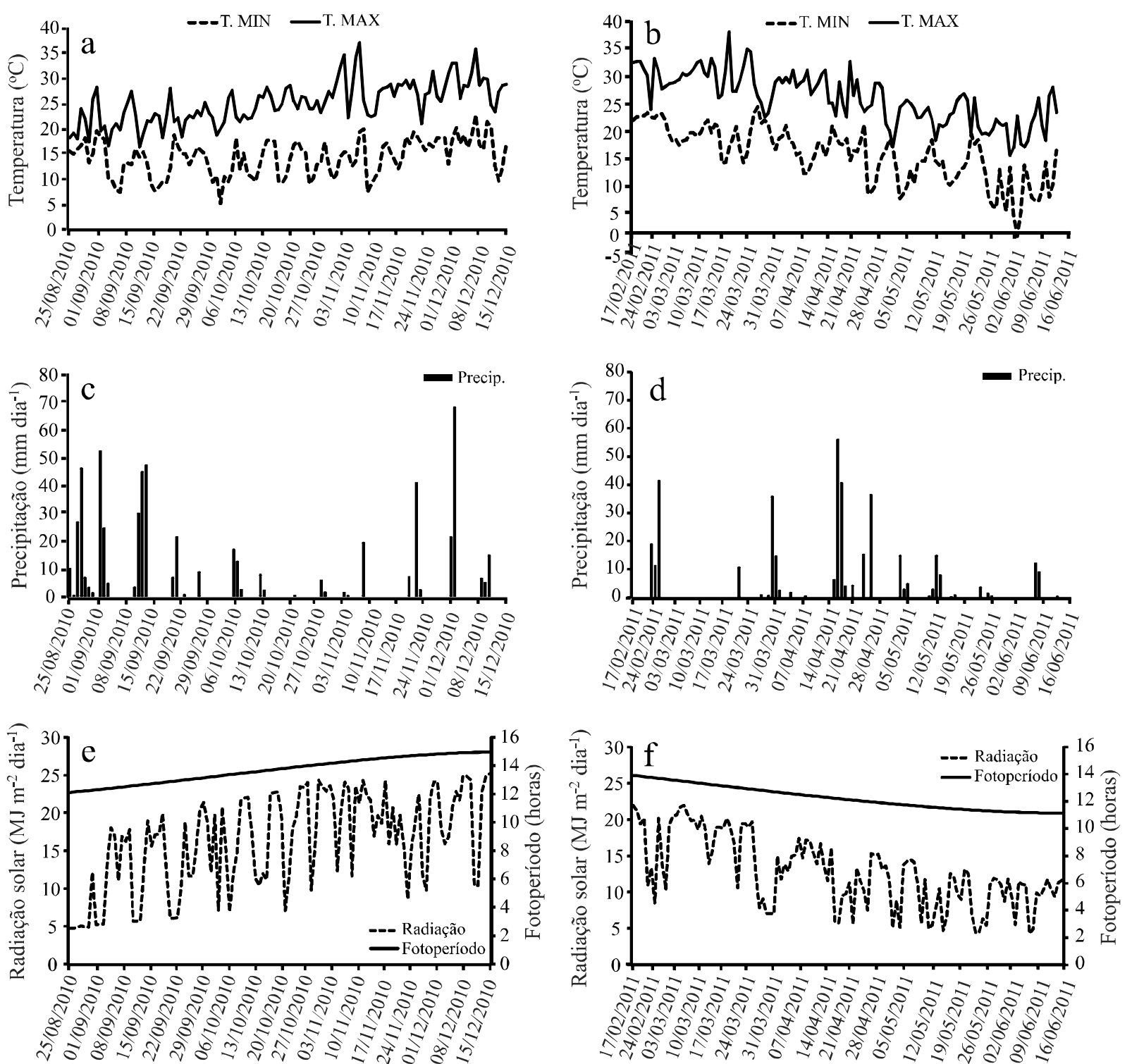

a cultivar Macaca, apresentando emergência mais rápida, principalmente no outono, indicando menor dormência dos tubérculos, o que é importante em regiões onde se faz dois cultivos anuais, caso da maioria das regiões produtoras de batata no Rio Grande do Sul.

Comparando os dois cultivos e descontandose a fase PL-EM, a duração das outras duas fases do ciclo de desenvolvimento (EM-IT e IT-IS) dos clones e cultivares de batata foram em geral menores no cultivo de outono (Figura 2), concordando com estudos anteriores (BISOGNIN et al., 2008; PAULA et al., 2005; STRECK et al., 2007). Uma das hipóteses para explicar

esse resultado, é o fotoperíodo médio da fase EM-IT no cultivo de outono $(12,5 \mathrm{~h})$ ter sido menor do que a média do fotoperíodo dessa mesma fase na primavera (13,2 h), ou seja, houve uma menor indução ao início de tuberização na primavera devido aumento do fotoperíodo (Figura 1e) e maior indução ao início de tuberização no outono devido a diminuição do fotoperíodo (Figura 1f). De acordo com Streck et al. (2007), as condições de fotoperíodo mais curto ou a diminuição do fotoperíodo ao longo do desenvolvimento vegetativo favorecem o início da tuberização, reduzindo assim a duração da fase EMIT no cultivo de outono na maioria dos clones estudados, 
Figura 2 - Duração, em dias, das fases de desenvolvimento plantio-emergência (PL-EM), emergência-início da tuberização (EM-IT) e início da tuberização-início da senescência (IT-IS) de doze genótipos de batata no cultivo de primavera 2010 (a) e no cultivo de outono 2011 (b). Santa Maria, RS, 2010-2011
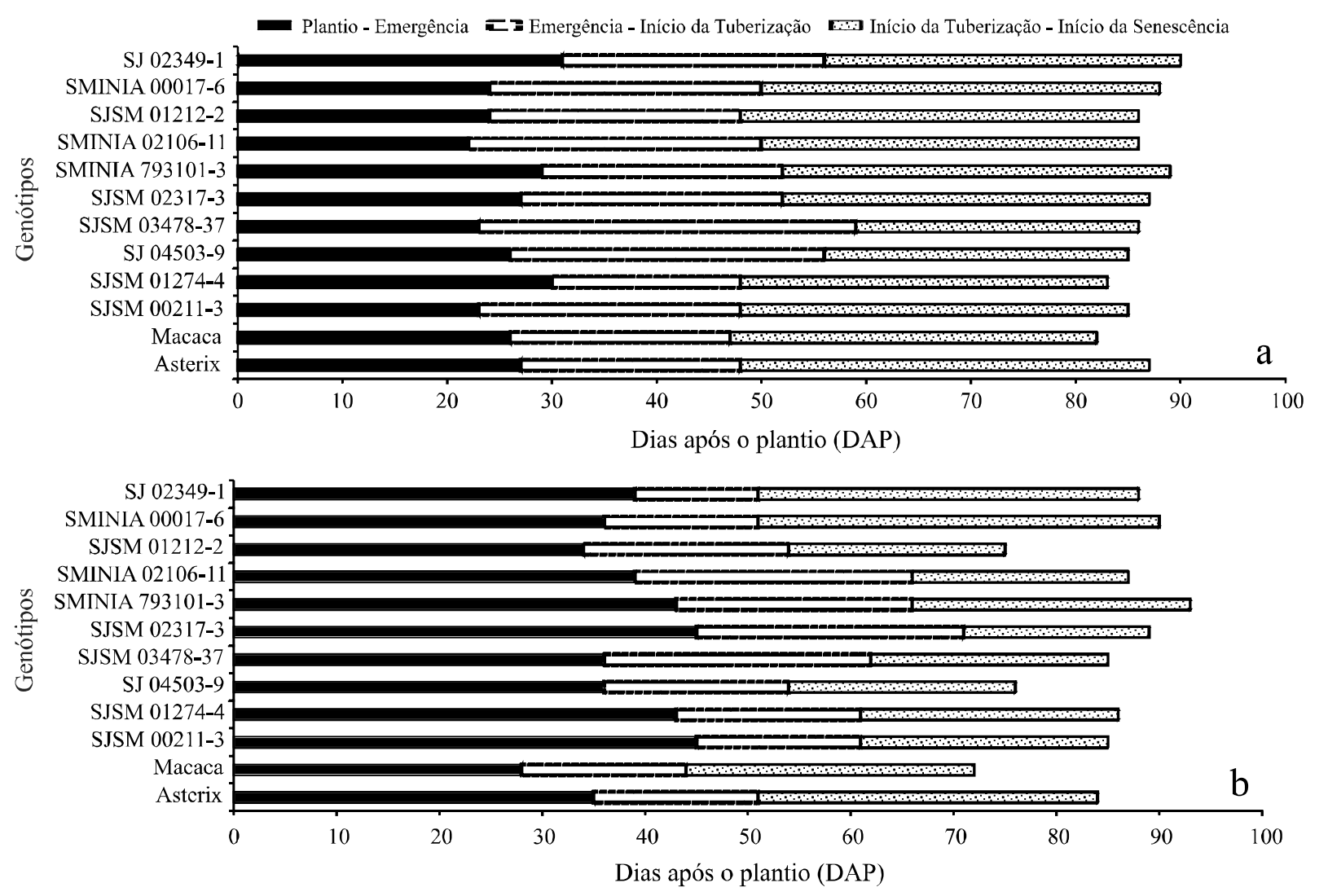

reforçando a hipótese da cultura da batata ser uma planta de dia curto para o início da tuberização (HELDWEIN; STRECK; BISOGNIN, 2009).

A maior duração da fase IT-IS no cultivo de primavera pode ser explicada pela exposição das plantas a temperaturas supra-ótimas no final do ciclo de desenvolvimento da cultura da batata em novembro e dezembro de 2010. Já no cultivo de outono, essa mesma fase ocorreu nos meses de abril e maio, quando as temperaturas eram mais amenas, reduzindo assim o intervalo de tempo para completar a tuberização e concordando com trabalhos de Bisognin et al. (2008) e Müller et al. (2009) que também verificaram a redução da fase IT-IS no cultivo de outono.

O número médio final de folhas (NFF) entre genótipos variou de 14,1 a 18,9 folhas no cultivo de primavera e de 16,9 a 22,8 folhas no cultivo de outono (Tabela 1). Esses valores de NFF são menores que os relatados por Bisognin et al. (2008) para os clones avançados SMIJ461-1, SMINIA793101-3, SMINIA97145-2 e a cultivar Macaca, que encontraram valores entre 21 e 29 folhas no cultivo de primavera/2006 e de 24 a 28 folhas no cultivo outono/2007 no mesmo local. Paula et al. (2005) também encontraram valores superiores de NFF para a cultivar Asterix (24 folhas) no cultivo de primavera neste local, porém o NFF no cultivo de outono (20 folhas), foi semelhante ao encontrado neste estudo. A variação no NFF médio entre épocas de cultivo pode estar associada às diferentes disponibilidades de fotoperíodo durante as estações de crescimento, na medida em que o florescimento é retardado em condições de dia curto (que é o caso do cultivo de outono) e consequentemente um maior número de folhas é produzido na haste principal (STRECK et al., 2009).

O filocrono variou de 17,0 a $21,5^{\circ} \mathrm{C}$ dia folha ${ }^{-1}$ no cultivo de primavera e de 14,8 a $22,1{ }^{\circ} \mathrm{C}$ dia folha ${ }^{-1}$ no cultivo de outono (Tabela 1 ). $\mathrm{O}$ filocrono encontrado para a cultivar Macaca neste estudo é próximo aos valores encontrados por Bisognin et al. (2008) no cultivo de primavera $\left(19,9^{\circ} \mathrm{C}\right.$ dia folha $\left.{ }^{-1}\right)$ e abaixo no cultivo de outono $\left(24,6{ }^{\circ} \mathrm{C}\right.$ dia folha $\left.{ }^{-1}\right)$, mas está entre os valores, $19,2{ }^{\circ} \mathrm{C}$ dia folha ${ }^{-1}$ e $22,9{ }^{\circ} \mathrm{C}$ dia folha ${ }^{-1}$, 
Tabela 1 - Médias do número final de folhas (NFF) e do filocrono $\left({ }^{\circ} \mathrm{C}\right.$ dia folha $\left.{ }^{-1}\right)$ na haste principal de doze genótipos de batata no cultivo de primavera 2010 e no cultivo de outono 2011. Santa Maria, RS, 2010-2011

\begin{tabular}{lcccc}
\hline \multirow{2}{*}{ Genótipos } & \multicolumn{2}{c}{ Cultivo de Primavera } & \multicolumn{2}{c}{ Cultivo de Outono } \\
\cline { 2 - 5 } & NFF & Filocrono & $17,9 \mathrm{~cd}$ & Filocrono \\
\hline SJSM 02349-1 & $16,5 \mathrm{bcd} *$ & $20,5 \mathrm{abc}$ & $20,4 \mathrm{~b}$ & $19,5 \mathrm{abc}$ \\
SMINIA 00017-6 & $16,4 \mathrm{bcd}$ & $18,0 \mathrm{abc}$ & $20,5 \mathrm{~b}$ & $16,8 \mathrm{bcd}$ \\
SJSM 01212-2 & $15,6 \mathrm{cde}$ & $18,7 \mathrm{abc}$ & $18,4 \mathrm{bcd}$ & $22,1 \mathrm{a}$ \\
SMINIA 02106-11 & $16,2 \mathrm{bcde}$ & $17,7 \mathrm{abc}$ & $18,9 \mathrm{bcd}$ & $17,4 \mathrm{bcd}$ \\
SMINIA 793101-3 & $15,6 \mathrm{cde}$ & $17,0 \mathrm{c}$ & $18,1 \mathrm{~cd}$ & $14,8 \mathrm{~d}$ \\
SJSM 02317-3 & $17,0 \mathrm{abc}$ & $21,1 \mathrm{ab}$ & $18,8 \mathrm{bcd}$ & $19,7 \mathrm{abc}$ \\
SJSM 03478-37 & $14,5 \mathrm{de}$ & $17,8 \mathrm{abc}$ & $16,9 \mathrm{~d}$ & $18,6 \mathrm{abcd}$ \\
SJSM 04503-9 & $14,1 \mathrm{e}$ & $20,1 \mathrm{abc}$ & $19,2 \mathrm{bc}$ & $16,5 \mathrm{bcd}$ \\
SJSM 01274-4 & $16,2 \mathrm{bcde}$ & $19,6 \mathrm{abc}$ & $22,8 \mathrm{a}$ & $20,3 \mathrm{ab}$ \\
SJSM 00211-3 & $17,9 \mathrm{ab}$ & $18,8 \mathrm{abc}$ & $20,4 \mathrm{~b}$ & $18,0 \mathrm{abcd}$ \\
Macaca & $17,1 \mathrm{abc}$ & $21,5 \mathrm{a}$ & $19,7 \mathrm{bc}$ & $19,0 \mathrm{abc}$ \\
Asterix & $18,9 \mathrm{a}$ & $17,4 \mathrm{bc}$ & 19,3 & 18,2 \\
Média Geral & 16,3 & 19,0 & 4,97 & 9,69 \\
CV\% ** & 5,82 & 9,63 &
\end{tabular}

* Médias seguidas pela mesma letra minúsculas na vertical não diferem pelo teste Tukey ao nível de $5 \%$ de erro; ** Coeficiente de variação

encontrados por Dellai et al. (2005), em Santa Maria, para a cultura da batata, em diferentes densidades de plantio.

A função matemática que melhor se ajustou aos dados de área de folhas individuais $\left(\mathrm{cm}^{2}\right)$ e comprimento da folha $(\mathrm{cm})$ foi a função potência $\left(y=a x^{b}\right)$. Os coeficientes "a" e "b" foram estimados para cada clone de batata e o ${ }^{2}$ foi elevado (variação de 0,861 a 0,976), o que indica que a área de folhas individuais pode ser estimada a partir do seu comprimento com boa precisão.

As cultivares Macaca e Asterix tiveram evoluções de IAF distintas ao longo das estações de crescimento (Figura 3). Asterix teve uma menor taxa de crescimento do IAF no início do ciclo e um menor IAFmax, porém o IAF permaneceu próximo do valor máximo mais tempo. Já a cultivar Macaca teve uma maior taxa de crescimento do IAF no início do ciclo e um maior IAFmax, que foi atingido cedo no ciclo de desenvolvimento, porém decresceu rapidamente. Esse decréscimo acentuado é atribuído ao auto-sombreamento das folhas basais, o que provocou a senescência das mesmas. Os clones avançados apresentaram evoluções do IAF semelhante a cultivar Asterix ao longo do ciclo de desenvolvimento, com exceção do clone SMINIA00017-6, no cultivo de primavera, e dos clones SMINIA793101-3, SMINIA00017-6 e SJSM01212-2, no cultivo de outono, que tiveram evolução do IAF ao longo da estação de crescimento semelhante a cultivar Macaca.
Os valores de IAFmax encontrados nesse trabalho são inferiores aos relatados em regiões de clima tropical ou temperado, os quais podem variar de 3 a 6, dependendo da época de cultivo e região (AGUIAR NETTO; RODRIGUES; PINHO, 2000) chegando até 7,5 (KOOMAN; RABBINGE, 1996). Trentin (2006) avaliando sistemas de previsão de ocorrência de Phytophthora infestans em batata no mesmo local deste estudo (Santa Maria), encontrou valores de IAFmax variando de 1,4 a 3,4 para o clone SMIJ461-1 e de 1,2 a 3,0 para cultivar Asterix, respectivamente em cultivo de primavera e cultivo de outono.

Houve diferença na massa da matéria fresca (Tabela 2) e seca (dados não mostrados) de tubérculos entre os genótipos, nos três tipos de tamanho (pequeno, médio e grande) e no total (soma dos três tipos). No cultivo de primavera, a maior produtividade total foi da cultivar Asterix, que não diferiu dos clones SJSM02349-1, SMINIA00017-6 e SMINIA793101 (variação de 30 a $46 \mathrm{t} \mathrm{ha}^{-1}$ ) e a menor produtividade foi nos clones

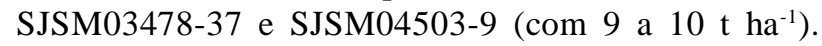
No cultivo de outono, a cultivar Macaca teve a maior produtividade não diferindo de vários clones (variação de 25 a $30 \mathrm{t} / \mathrm{ha}$ ) e a menor produtividade foi do clone SJSM00211-3 que produziu 17,7 $\mathrm{tha}^{-1}$.

Em ambos os cultivos os clones avançados apresentaram elevada produtividade de tubérculos 
Figura 3 - Evolução do índice de área foliar (IAF) de doze genótipos de batata no cultivo de primavera 2010 (a) e no cultivo de outono 2011 (b). Santa Maria, RS, 2010-2011
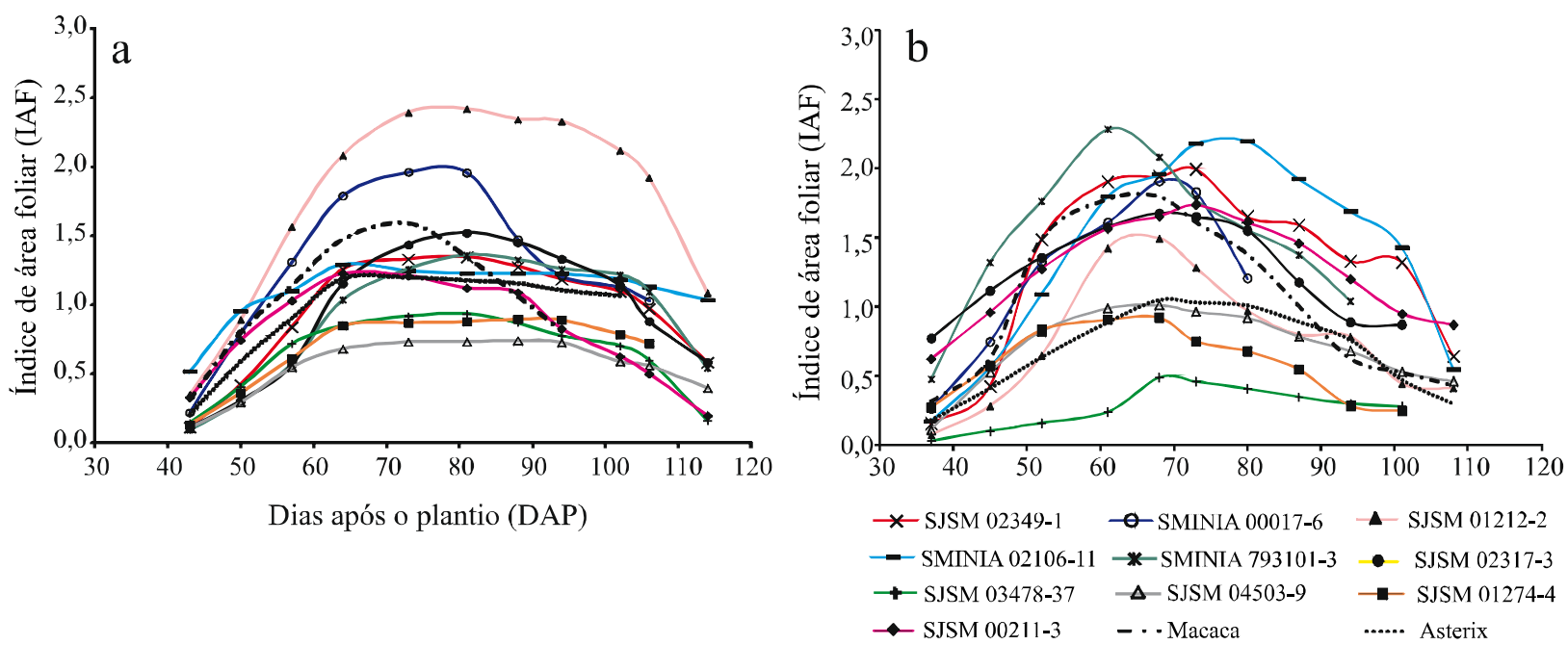

Tabela 2 - Produtividade $\left(\mathrm{kg} \mathrm{ha}^{-1}\right)$ de massa da matéria fresca de tubérculos pequenos, médios, grandes e total de doze clones de batata no cultivo de primavera 2010 e no cultivo de outono 2011. Santa Maria, RS, 2010-2011

\begin{tabular}{|c|c|c|c|c|}
\hline \multirow{2}{*}{ Genótipos } & \multicolumn{4}{|c|}{ Massa fresca de tubérculos $\left(\mathrm{kg} \mathrm{ha}^{-1}\right)$} \\
\hline & Pequenos & Médios & Grandes & Total \\
\hline \multicolumn{5}{|c|}{ 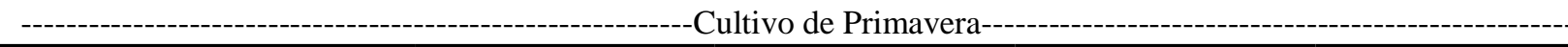 } \\
\hline SJSM 02349-1 & $2229 \mathrm{ab}^{*}$ & $5170 \mathrm{bc}$ & $22592 \mathrm{ab}$ & $30251 \mathrm{ab}$ \\
\hline SMINIA 00017-6 & $2525 \mathrm{ab}$ & $7516 \mathrm{abc}$ & $21641 \mathrm{ab}$ & $31831 \mathrm{ab}$ \\
\hline SJSM 01212-2 & 5099 a & $9389 a b$ & $12692 \mathrm{bcd}$ & $27614 b$ \\
\hline SMINIA 02106-11 & $2090 \mathrm{~b}$ & $6653 \mathrm{abc}$ & $13439 \mathrm{bcd}$ & 22344 bc \\
\hline SMINIA 793101-3 & $4017 \mathrm{ab}$ & $10849 \mathrm{a}$ & $18331 \mathrm{bc}$ & $33349 \mathrm{ab}$ \\
\hline SJSM 02317-3 & $2641 \mathrm{ab}$ & $4482 \mathrm{bc}$ & $16372 \mathrm{bcd}$ & $23637 \mathrm{bc}$ \\
\hline SJSM 03478-37 & $2013 \mathrm{~b}$ & $2934 \mathrm{c}$ & $4322 \mathrm{~d}$ & $9306 \mathrm{c}$ \\
\hline SJSM 04503-9 & $1083 \mathrm{~b}$ & $2735 c$ & $6004 \mathrm{~cd}$ & $9872 \mathrm{c}$ \\
\hline SJSM 01274-4 & $1213 \mathrm{~b}$ & $4173 \mathrm{bc}$ & $16710 \mathrm{bcd}$ & $22112 b c$ \\
\hline SJSM 00211-3 & $2629 \mathrm{ab}$ & $7833 \mathrm{abc}$ & $18603 \mathrm{bc}$ & 29223 b \\
\hline Macaca & $3047 \mathrm{ab}$ & $8819 a b$ & $12378 \mathrm{bcd}$ & $24472 \mathrm{bc}$ \\
\hline Asterix & $2618 \mathrm{ab}$ & $7876 \mathrm{abc}$ & 35467 a & 45980 a \\
\hline $\mathrm{CV}(\%)^{* *}$ & 48,0 & 35,7 & 35,5 & 25,9 \\
\hline \multicolumn{5}{|c|}{ 1- } \\
\hline SJSM 02349-1 & $1048 \mathrm{ab}^{*}$ & $3454 \mathrm{bc}$ & $22266 \mathrm{abc}$ & $26768 \mathrm{abcd}$ \\
\hline SMINIA 00017-6 & $737 \mathrm{~b}$ & $2934 \mathrm{c}$ & $24640 \mathrm{ab}$ & $28311 \mathrm{abc}$ \\
\hline SJSM 01212-2 & $1313 \mathrm{ab}$ & $6399 \mathrm{bc}$ & $26360 \mathrm{a}$ & 34072 a \\
\hline SMINIA 02106-11 & $1320 \mathrm{ab}$ & $4563 \mathrm{bc}$ & $19750 \mathrm{abcd}$ & $25633 \mathrm{abcd}$ \\
\hline SMINIA 793101-3 & $755 \mathrm{~b}$ & $3300 \mathrm{bc}$ & $19436 \mathrm{abcd}$ & $23493 \mathrm{~cd}$ \\
\hline SJSM 02317-3 & $752 b$ & 2932 c & $19413 \mathrm{abcd}$ & $23097 \mathrm{~cd}$ \\
\hline SJSM 03478-37 & $1217 \mathrm{ab}$ & $3067 \mathrm{c}$ & $21744 \mathrm{abcd}$ & $26029 \mathrm{abcd}$ \\
\hline SJSM 04503-9 & $1314 \mathrm{ab}$ & $5999 \mathrm{ab}$ & $25640 \mathrm{a}$ & $32953 \mathrm{ab}$ \\
\hline
\end{tabular}


Continuação Tabela 2

\begin{tabular}{lcccc}
\hline SJSM 01274-4 & $673 \mathrm{~b}$ & $3312 \mathrm{bc}$ & $22018 \mathrm{abc}$ & $26004 \mathrm{abcd}$ \\
SJSM 00211-3 & $563 \mathrm{~b}$ & $3096 \mathrm{c}$ & $14102 \mathrm{~d}$ & $17762 \mathrm{~d}$ \\
Macaca & $2362 \mathrm{a}$ & $10566 \mathrm{a}$ & $17694 \mathrm{bcd}$ & $30622 \mathrm{abc}$ \\
Asterix & $1568 \mathrm{ab}$ & $7097 \mathrm{ab}$ & $15540 \mathrm{~cd}$ & $24206 \mathrm{bcd}$ \\
CV(\%)** & 58,6 & 37,4 & 17,7 & 16,5 \\
\hline
\end{tabular}

* Médias seguidas pela mesma letra minúsculas na vertical não diferem pelo teste Tukey ao nível de 5\% de erro; ** Coeficiente de Variação

(Tabela 2), superiores à produtividade média no estado do Rio Grande do Sul que é de 17,2 t ha-1 (INSTITUTO BRASILEIRO DE GEOGRAFIA E ESTATÍSTICA, 2011), com exceção apenas dos clones SJSM03478-37 e SJSM04503-9, no cultivo de primavera, e do clone SJSM00211-3, no cultivo de outono, indicando o elevado potencial produtivo dos clones avançados do PGMB/ UFSM. A produtividade de tubérculos, na maioria dos clones avançados (SJSM02349-1, SMINIA000176, SJSM01212-2, SMINIA793101-3, SJSM02317-3, SJSM01274-4 e SJSM00211-3) foi maior no cultivo de primavera, concordando com os trabalhos de Bisognin et al. (2008) e Müller et al. (2009). Esse resultado pode ser explicado pela maior disponibilidade de radiação solar e maior duração da fase de tuberização no cultivo de primavera (BISOGNIN et al., 2008; SALAZAR et al., 2008; SILVA; PINTO, 2005), haja visto que as diferenças de temperatura média na fase de tuberização foram pequenas $\left(20,3{ }^{\circ} \mathrm{C}\right.$ na primavera e $18,4{ }^{\circ} \mathrm{C}$ no outono).
Segundo Bisognin et al. (2008), a seleção de clones adaptados ao cultivo de primavera e outono em regiões subtropicais deve ser baseada na soma das produtividades de tubérculos nas duas estações de cultivo. A soma das produtividades de tubérculos em matéria fresca (MF) e seca (MS) do cultivo de primavera e de outono indicou que para a variável MF de tubérculos, a cultivar Asterix (56.783 $\mathrm{kg} \mathrm{ha}^{-1}$ ) e o clone SJSM02349-1 (53.116 ha-1) apresentaram as maiores produtividades (Tabela 3). Os demais clones, com exceção do SJSM03478-37, não diferiram do mais produtivo. Para MS de tubérculos, a cultivar mais produtiva foi a Asterix, e somente o clone SJSM03478-37 diferiu desta (Tabela 3). Portanto, de acordo com o critério de seleção de Bisognin et al. (2008), o clone SJSM03478-37 é menos adaptado aos cultivos de primavera e outono em regiões subtropicais, quando comparado aos demais clones utilizados neste estudo.

Tabela 3 - Soma das produtividades de massa da matéria fresca e seca de tubérculos de doze genótipos de batata no cultivo de primavera 2010 e no cultivo de outono 2011. Santa Maria, RS, 2010-2011

\begin{tabular}{lcc}
\hline \multicolumn{1}{c}{ Genótipos } & Massa fresca $\left(\mathrm{kg} \mathrm{ha}^{-1}\right)$ & Massa seca $\left(\mathrm{kg} \mathrm{ha}^{-1}\right)$ \\
\hline SJSM 02349-1 & $53116 \mathrm{a}^{*}$ & $9063 \mathrm{ab}$ \\
SMINIA 00017-6 & $50449 \mathrm{ab}$ & $9981 \mathrm{ab}$ \\
SJSM 01212-2 & $44178 \mathrm{ab}$ & $8571 \mathrm{ab}$ \\
SMINIA 02106-11 & $38099 \mathrm{ab}$ & $7445 \mathrm{ab}$ \\
SMINIA 793101-3 & $43418 \mathrm{ab}$ & $8161 \mathrm{ab}$ \\
SJSM 02317-3 & $38131 \mathrm{ab}$ & $7621 \mathrm{ab}$ \\
SJSM 03478-37 & $29148 \mathrm{~b}$ & $5976 \mathrm{~b}$ \\
SJSM 04503-9 & $41252 \mathrm{ab}$ & $7398 \mathrm{ab}$ \\
SJSM 01274-4 & $39863 \mathrm{ab}$ & $7658 \mathrm{ab}$ \\
SJSM 00211-3 & $33994 \mathrm{ab}$ & $6781 \mathrm{ab}$ \\
Macaca & $44739 \mathrm{ab}$ & $8211 \mathrm{ab}$ \\
Asterix & $56783 \mathrm{a}$ & $10684 \mathrm{a}$ \\
CV\%** & 18,2 & 19,1 \\
\hline
\end{tabular}

* Médias seguidas pela mesma letra minúsculas na vertical não diferem pelo teste Tukey ao nível de 5 de erro; ** Coeficiente de variação 
Tabela 4 - Valores da correlação de Pearson e da probabilidade (entre parênteses) entre a variável produtividade de massa seca de tubérculos $\left(\mathrm{kg} \mathrm{ha}^{-1}\right)$ e as variáveis duração (dias) das fases emergência-início de senescência (EM-IS), plantio-emergência (PL-EM), emergência-início de tuberização (EM-IT), início de tuberização-início de senescência (IT-IS), índice de área foliar no início de tuberização (IAF no IT), índice de área foliar máximo (IAF max), número de folhas na haste principal (folhas planta ${ }^{-1}$ ) no início de tuberização (NF no IT), número final de folhas na haste principal (NFF), massa seca de frutos (MS Frutos) por planta (g planta ${ }^{-1}$ ) e massa seca da parte aérea (MS Parte Aérea) por planta (g planta $^{-1}$ ) de doze genótipos de batata no cultivo de primavera 2010 e no cultivo de outono 2011. Santa Maria, RS, 2010-2011

\begin{tabular}{|c|c|c|}
\hline Variaveis & Cultivo de Primavera & Cultivo de Outono \\
\hline EM-IS & $0,12558(0,6967)^{\mathrm{ns}}$ & $-0,05291(0,8703)^{\mathrm{ns}}$ \\
\hline PL-EM & $0,16613(0,6058)^{\mathrm{ns}}$ & $-0,76738(0,0036) * *$ \\
\hline EM-IT & $-0,62123(0,0311)^{*}$ & $0,08783(0,7861)^{\mathrm{ns}}$ \\
\hline IT-IS & $0,91760(0,0001)^{* *}$ & $-0,10167(0,7532)^{\mathrm{ns}}$ \\
\hline IAF no IT & $0,57609(0,0499)^{*}$ & $0,14365(0,6560)^{\mathrm{ns}}$ \\
\hline NF no IT & $0,69865(0,0115)^{* *}$ & $-0,03786(0,9070)^{\mathrm{ns}}$ \\
\hline IAFmax & $0,49716(0,1001)^{\mathrm{ns}}$ & $-0,32580(0,3014)^{\mathrm{ns}}$ \\
\hline NFF & $0,78046(0,0027)^{*}$ & $-0,26074(0,4130)^{\mathrm{ns}}$ \\
\hline MS Frutos & $-0,18298(0,5692)^{\mathrm{ns}}$ & - \\
\hline MS Parte Aérea & $-0,56653(0,0548)^{*}$ & - \\
\hline
\end{tabular}

ns= não significativo; $*$ = significativo a $5 \% ; * *=$ significativo a $1 \% ;-$ = não foi avaliado

As correlações entre a variável produtividade de MFe MS de tubérculos com as demais variáveis analisadas foram similares e, assim, optou-se por apresentar somente os valores das correlações com a produtividade de MS de tubérculos (Tabela 4). No cultivo de outono, não foram avaliadas as variáveis massa seca de frutos e a massa da matéria seca da parte aérea. A primeira variável não foi coletada porque nesse cultivo as plantas não foram estimuladas a florescer, portanto a produção de frutos foi desprezível. Em alguns dias, durante o final do ciclo de desenvolvimento no cultivo de outono, ocorreu a formação de geada sobre as plantas de batata, reduzindo consideravelmente a parte aérea, por esse motivo optou-se por não avaliar a MS da mesma.

Aduração do ciclo de desenvolvimento da cultura da batata (EM-IS) não se correlacionou com a produtividade de MS de tubérculos (Tabela 4), divergindo dos resultados encontrados em regiões tropicais e temperadas do Brasil, onde as cultivares de ciclo longo são mais produtivas que as de ciclo precoce (RODRIGUES et al., 2009; SILVA et al., 2009; SILVA; PINTO, 2005). Houve correlação negativa com a fase PL-EM no cultivo de outono e com a fase EMIT no cultivo de primavera e correlação positiva com a fase IT-IS no cultivo de primavera (Tabela 4). Esses resultados indicam que em regiões subtropicais, a duração de algumas fases, e não do ciclo total, de desenvolvimento da cultura da batata determinam a produtividade de tubérculos.

A correlação negativa com a duração da fase PLEM no cultivo de outono pode ser explicada pelo longo período de dormência dos tubérculos, que provocou atraso e heterogeneidade da emergência, fazendo com que as primeiras plantas que emergiram ficassem expostas a uma radiação solar de $17,9 \mathrm{MJ} \mathrm{m}^{-2} \mathrm{dia}^{-1}$, enquanto as últimas plantas que emergiram no cultivo de outono fossem expostas à radiação solar de $12,3 \mathrm{MJ} \mathrm{m}^{-2} \operatorname{dia}^{-1}$. A disponibilidade média de radiação solar no cultivo de outono nas fases de EM-IT e IT-IS foi de $13 \mathrm{MJ} \cdot \mathrm{m}^{-2} \cdot \mathrm{dia}^{-1}$ e 10,7 MJ.m-2 dia $^{-1}$, que são valores baixos e próximos aos níveis tróficos da cultura da batata (HELDWEIN; STRECK; BISOGNIN, 2009) e nesta situação a planta produz apenas os fotoassimilados necessários para sua manutenção.

A correlação negativa da MS de tubérculos com a duração da fase EM-IT no cultivo de primavera ocorreu pela antecipação do início de tuberização, aumentando assim a fase IT-IS (correlação positiva), ou seja, maior o período de enchimento de tubérculos, corroborando com resultados encontrados por Silva et al. (2009) em Lavras, MG, que também verificaram uma correlação alta e positiva entre a duração da fase tuberização com o aumento da produtividade de tubérculos. Resultados similares foram também obtidos por Paula et al. (2005) em Santa Maria, RS, que além de encontrar correlação positiva com a duração da fase IT-IS, verificaram uma correlação baixa e negativa da duração da fase EM-IT com o rendimento de tubérculos.

No cultivo de primavera observou-se também uma correlação positiva da MS de tubérculos com o NFF, IAF no IT e principalmente com o NF no IT, confirmando a hipótese de que clones com maior vigor inicial, ou seja, 
maior IAF e número de folhas acumuladas na haste principal no início de tuberização são os mais produtivos e estes podem ser utilizados como um critério de seleção. Já a correlação negativa com a MS da parte aérea pode ser explicada pela quantidade elevada de carboidratos destinados ao crescimento da parte vegetativa da planta em detrimento da translocação para acumulação e armazenagem de amido nos tubérculos.

A expectativa de uma correlação positiva da produtividade com a variável IAFmax não foi confirmada neste estudo. Duas possíveis hipóteses para este resultado podem ser o baixo IAFmax alcançado pelos clones, e também a arquitetura da planta destes clones de batata, na qual predomina a disposição horizontal das folhas, o que dificulta a entrada de radiação solar no dossel vegetativo, causando auto-sombreamento precoce. Não houve correlação entre MS de tubérculos e massa seca de frutos, indicando que a quantidade de fotoassimilados translocados pela planta para produção desses frutos foi baixa, a ponto de não afetar a produtividade de tubérculos.

No cultivo de outono ocorreu um encurtamento da fase EM-IT na maioria dos genótipos de batata, devido ao desenvolvimento das plantas ter ocorrido num fotoperíodo decrescente, o qual induziu o início da tuberização (Streck et al., 2007). O encurtamento da fase vegetativa nesse cultivo promoveu uma elevada competição por fotoassimilados, devido ao crescimento simultâneo entre os órgãos vegetativos e reprodutivos, o que explica não ter ocorrido correlação significativa entre a duração das fases vegetativa e de tuberização com a MS de tubérculos.

\section{CONCLUSÕES}

1. O desenvolvimento das plantas de batata varia em função do genótipo em cada época de cultivo;

2. Em regiões subtropicais, a duração das fases emergênciainício de tuberização e início de tuberização-início de senescência determinam a produtividade de tubérculos;

3. Exceto o clone SJSM 03478-37, os clones avançados apresentam elevada produção de tubérculos e boa adaptação às duas épocas de cultivo em ambiente subtropical do Rio Grande do Sul.

\section{REFERÊNCIAS}

AGUiAR NetTO, A. O.; RODRIGUES, J. D.; PINHO, S. Z. Análise de crescimento na cultura da batata submetida a diferentes laminas de irrigação. Pesquisa Agropecuária Brasileira, v. 35, n. 5, p. 901-907, 2000.
ARNOLD, C. Y. Maximum-minimum temperature as a basis for computing heat units. Proceedings of the American Society for Horticultural Science, v. 76, n. 1, p. 682-692, 1960.

BISOGNIN, D. A. et al. Desenvolvimento e rendimento de clones de batata na primavera e no outono. Pesquisa Agropecuária Brasileira, v. 43, n. 6, p. 699-705, 2008.

BURIOL, G. A. et al. Disponibilidade de radiação solar para o cultivo do tomateiro durante o inverno no Estado do Rio Grande do Sul. Pesquisa Agropecuária Gaúcha, v. 6, n. 1, p. 113-120, 2000.

BURIOL, G. A. et al. Homogeneidade da radiação solar global medida nas estações meteorológicas da Fundação Estadual de Pesquisa Agropecuária do Estado do Rio Grande do Sul, Brasil. Pesquisa Agropecuária Gaúcha, v. 12, n. 1/2, p. 65-72, 2006.

DELLAI, J. et al. Filocrono em diferentes densidades de plantas de batata. Ciência Rural, v. 35, n. 6, p. 1269-1274, 2005.

HELDWEIN, A. B.; STRECK, N. A.; BISOGNIN, D. A. Batata. In: MONTEIRO, J. E. B. A. Agrometeorologia dos cultivos: o fator meteorológico na produção agrícola. Brasília: Instituto Nacional de Meteorologia, 2009. cap. 2, p. 281-293.

INSTITUTOBRASILEIRODEGEOGRAFIAEESTATÍSTICA. Estatística da Produção Agrícola. 2011. Disponível em: <http:// www.ibge.gov.br>. Acesso em: 28 dez. 2011.

KOOMAN, P. L.; RABBINGE, R. An analysis of the relationship between dry matter allocation to the tuber and earliness of a potato crop. Annals of Botany, v. 77, n. 3, p. 235-242, 1996.

KUINCHTNER, A; BURIOL, G. A. Clima do Estado do Rio Grande do Sul segundo a classificação climática de Köppen e Thornthwaite. Disciplinarum Scientia, v. 2, p. 171-182, 2001.

MENEZES, C. B. et al. Combining ability of potato genotypes for cool and warm seasons in Brazil. Crop Breeding and Applied Biotechnology, v. 1, n. 2, p. 145-157, 2001.

MÜLLER, D. R. et al. Dormência e dominância apical de diferentes tamanhos de tubérculos de batata. Ciência Rural, v. 40, n. 12, p. 2454-2459, 2010.

MÜLLER, D. R. et al. Expressão dos caracteres e seleção de clones de batata nas condições de cultivo de primavera e outono. Ciência Rural, v. 39, n. 5, p. 1237-1334, 2009.

PAULA, F. L. M. et al. Soma térmica de algumas fases do ciclo de desenvolvimento da batata (Solanum tuberosum L.). Ciência Rural, v. 35, n. 5, p. 1034-1042, 2005.

RODRIGUES, G. B. et al. Seleção para duração do ciclo vegetativo em batata e relação com a produtividade de tubérculos. Horticultura Brasileira, v. 27, n. 3, p. 280-285, 2009.

SALAZAR, M. R. et al. A model for the potential production and dry matter distribution of cape gooseberry (Physalis peruviana L.). Scientia Horticulturae, v. 115, n. 2, p. 142-148, 2008.

SILVA, L. A. S. et al. Caracterização morfofisiológica de clones precoces e tardios de batata visando à adaptação a condições tropicais. Bragantia, v. 68, n. 2, p. 295-302, 2009. 
SILVA, L. A. S.; PINTO, C. A. B. P. Duration of the growth cycle and the yield potential of potato genotypes. Crop Breeding and Applied Biotechnology, v. 5, p. 20-28, 2005.

SOUZA, Z. S. Melhoramento da batata para processamento industrial em condição subtropical e temperada do sul do Brasil. 2010. 134 f. Tese (Doutorado em Agronomia) Universidade Federal de Santa Maria, Santa Maria, 2010.

STRECK, N. A. et al. Simulating the development of field grown potato (Solanum tuberosum L.). Agricultural and Forest Meteorology, v. 142, n. 1, p.1-11, 2007.

STRECK, N. A. et al. Filocrono em batateira afetado pelo tamanho do tubérculo-semente e pela época de cultivo. Bragantia, v. 68, n. 1, p. 137-143, 2009.
TREnTIN, G. Avaliação de sistemas de previsão de ocorrência de Phytophthora infestans em Batata. 2006. 102 f. Dissertação (Mestrado em Agronomia) Universidade Federal de Santa Maria, Santa Maria, 2006.

VISSER, R. G. F. et al. Sequencing the potato genome: outline and first results to come from the elucidation of the sequence of the world's third most important food crop. American Journal of Potato Research , v. 86 , n. 6, p. 417429, 2009.

XUE, Q.; WEISS, A.; BAENZIGER, P. S. Predicting leaf appearance infield grown winter wheat: evaluating linear and non - linear models. Ecological Modelling, v. 175, n. 3, p. 261-270, 2004. 